This item was submitted to Loughborough's Research Repository by the author.

Items in Figshare are protected by copyright, with all rights reserved, unless otherwise indicated.

\title{
Fibre distribution and tensile response anisotropy in sprayed fibre reinforced concrete
}

PLEASE CITE THE PUBLISHED VERSION

https://doi.org/10.1617/s11527-018-1156-5

\section{PUBLISHER}

@Rilem. Published by Springer Verlag

VERSION

AM (Accepted Manuscript)

\section{PUBLISHER STATEMENT}

This work is made available according to the conditions of the Creative Commons Attribution-NonCommercialNoDerivatives 4.0 International (CC BY-NC-ND 4.0) licence. Full details of this licence are available at: https://creativecommons.org/licenses/by-nc-nd/4.0/

\section{LICENCE}

CC BY-NC-ND 4.0

\section{REPOSITORY RECORD}

Segura-Castillo, Luis, Sergio H. Cavalaro, Chris I. Goodier, Antonio Aguado, and Simon A. Austin. 2019. "Fibre Distribution and Tensile Response Anisotropy in Sprayed Fibre Reinforced Concrete". figshare. https://hdl.handle.net/2134/28480. 


\title{
FIBRE DISTRIBUTION AND TENSILE RESPONSE ANISOTROPY IN SPRAYED FIBRE REINFORCED CONCRETE
}

Luis Segura-Castillo', Sergio H.P. Cavalaro², Chris Goodier ${ }^{3}$, Antonio Aguado², Simon Austin ${ }^{3}$

${ }^{1}$ Instituto de Estructuras y Transporte, Facultad de Ingeniería, Universidad de la República (UdelaR), J. Herrera y Reissig 565, 11300, Montevideo, Uruguay

e-mail: Isegura@fing.edu.uy / tel: (+598) 2711.0524 int. 113

Segura-Castillo Orcid: 0000-0002-9412-0542

${ }^{2}$ Department of Construction Engineering, Universitat Politècnica de Catalunya, UPC, Jordi Girona 1-3, 08034 Barcelona, Spain

Cavalaro Orcid: 0000-0002-9368-0898

Aguado Orcid: 0000-0001-5542-6365

${ }^{3}$ Department of Civil \& Building Engineering, Loughborough University, LE11 3TU Loughborough, UK

Goodier Orcid: 0000-0001-6464-4065

Austin Orcid: 0000-0001-9821-2244

\begin{abstract}
Sprayed, steel fibre reinforced concrete (SSFRC) is a material that tends to present anisotropy. The shearing conditions of the spraying process induce preferential fibre orientation. Despite the extensive use of the material, no study has been found about the assessment of fibre distribution and its influence on the residual tensile strength of SSFRC. The objective of this work is to address such issue from a quantitative standpoint. An experimental program was performed with specimens extracted from different directions within a SSFRC panel. The fibre content and 3D orientation were quantified for each specimen using the inductive method. Then, the tensile behaviour was indirectly assessed for the same specimen through the Barcelona test. Results confirm the high level of anisotropy of SSFRC. The fibre orientation number parallel to the spraying direction is 3 times bigger than that found in the perpendicular direction. Similar differences were observed between the residual tensile response measured in those directions. Comparison of test results suggest that the preferential fibre orientation creates weaker planes that favours the increase of crack opening at lower load levels.
\end{abstract}

Keywords: sprayed concrete; fibre reinforced concrete; anisotropy; fibre distribution; residual tensile behaviour 


\section{INTRODUCTION}

Since the early studies about fibre reinforced concrete (FRC), researchers have put forward the existence of preferential fibre orientation in the matrix. In probably one of the first references specifically addressing the phenomenon, Edgington and Hannant [1] indicated that fibres tend to align in planes at right angles to the direction of vibration or gravity. Nowadays, extensive research is available on the subject, showing that fibre orientation is also affected by the fresh-state properties of concrete, the wall-effects of the formwork, the casting procedure and the flow paths [2]-[6].

The high interest about fibre orientation does not arise merely from a scientific perspective. A clear link exists between this parameter and the residual tensile strength of FRC. In fact, studies reveal variations of up 3 times in the postcracking performance of specimens depending on how they are produced and how this modifies fibre orientation in concrete [2], [7], [8]. The solid experimental evidence has led to the inclusion of special considerations in the most recent codes for the design of FRC structures. For example, the Model Code 2010 includes a coefficient that should be applied to account for fibre orientation in the design [9], [10]. As existing codes are updated, similar considerations are likely to be implemented.

The main fields of application of FRC in terms of volume consumed per year are pavements and underground constructions. In the latter, precast elements for lining and sprayed concrete comprise almost the totality of uses [11]. In the spraying process, concrete is pumped through a pipe, exits a nozzle at high speed and impacts over a surface. Part of the material rebounds (mainly coarser aggregate and fibres) and part consolidates over the surface, forming a hardened layer that might have structural responsibility. The shearing conditions applied to FRC in the process should have a direct influence on fibre orientation and, hence, in the mechanical performance of the structure.

In contrast with the widespread knowledge available for poured FRC, few studies from the literature address the influence of the spraying process in the fibre distribution. Armelin and Helene [12] remark a big variability in the fibre content of sprayed concrete, which is attributed to the rebound of fibres. Robins et al. [13] and Banthia et al. [14] found that the spraying process induces an alignment of fibres in a direction approximately parallel to the spraying surface and concluded that the sprayed FRC should, therefore, display high anisotropy in the residual tensile behaviour. Yet, this anisotropy has not been quantified for sprayed FRC. Such lack of experimental evidence may hinder the optimized and safe design of structures made with sprayed FRC in line with the most recent design codes, limiting the potential use of the material.

The objective of the present work is to assess the fibre distribution and its influence on the anisotropy of the residual tensile behaviour of sprayed, steel fibre reinforced concrete (SSFRC). An experimental program was performed with specimens extracted from different directions within a SSFRC panel. The fibre content and 3D orientation profile were quantified for each specimen using the inductive method. Then, the tensile behaviour was indirectly assessed for the same specimens through the Barcelona test. Finally, relations between both test results were established. Conclusions derived from this work contribute to the knowledge about scarcely studied aspects of SSFRC, providing reference data for future research and for the consideration of the structural responsibility of the material in codes and guidelines. 


\section{MATERIALS AND METHODOS}

\subsection{Spraying process and extraction of cores}

The production of SSFRC specimens imply the use of heavy spraying equipment and of significant amount of concrete. To emulate the conditions found in practice, an Aliva 503 wet-mix spraying robot was used. The production occurred in wintertime during the construction of a bi-layer diaphragm wall described in [15], [16]. The concrete had the following composition: $450 \mathrm{~kg} / \mathrm{m}^{3}$ of cement (CEM I $52.5 \mathrm{R}$ ), $180 \mathrm{l} / \mathrm{m}^{3}$ of water, $300 \mathrm{~kg} / \mathrm{m}^{3}$ of $4 / 12$ limestone aggregate, 975 $\mathrm{kg} / \mathrm{m}^{3}$ of $0 / 4$ sand, $355 \mathrm{~kg} / \mathrm{m}^{3}$ of $0 / 2$ corrector sand, $1.5 \%$ by cement weight (bcw) of nano-silicca, $1.5 \%$ bcw of superplasticizer and $30 \mathrm{~kg} / \mathrm{m}^{3}$ of DRAMIX RC-65/35BN fibres. The nano-silica was added to enhance the pumpability and the watertightness of the hardened sprayed layer. Steel fibres had hooked ends, $35 \mathrm{~mm}$ of length and approximately $0.54 \mathrm{~mm}$ of equivalent diameter.

The spraying was performed in 2 metallic moulds with $100 \times 80 \times 15 \mathrm{~cm}$ that followed the requirements and the shape specified in UNE-EN 14488-1:2006 [17]. The moulds were placed over the levelled floor at an angle of $20^{\circ}$ with the vertical wall, in accordance with the recommendations from same standard. In total, 2 panels were produced with the same batch of concrete. One was used for the control of compressive strength and the other, for assessment of fibre distribution, fibre content and residual tensile behaviour. After spraying, the concrete was kept in the moulds for 24 hours. During this period, the exposed surface of the panels was periodically wetted to reduce the loss of water due to evaporation. After that, the panels were taken to the lab, where they were taken from the moulds and prepared for the extraction of cores.

Cores for the assessment of fibre content and orientation were extracted with the distribution schematically represented in Fig. 1. The edges of the panel were trimmed off (see Fig. 1a: Mould boundary). These trimmed parts did not have enough thickness and were not suitable for the experimental program due to the negative influence of the sloped edges of the moulds over the quality of the sprayed concrete. The panel was further cut into three blocks to facilitate the core extraction from different directions. Fig. 1a shows the panel after the cutting process.

Cores were extracted using a cylindrical drill bit with $100-\mathrm{mm}$ nominal external diameter and 93-mm internal diameter. The extraction was performed in the three main directions of the panel (Fig. 1b). Cores S1 to S14 were aligned with the spraying direction. Cores P1 to P6 were perpendicular to the spraying direction and aligned with the side of the panel that was almost vertical during the spraying process. Those labelled P7 to P13 were perpendicular to the spraying direction and aligned with the side of the panel that was horizontal during the spraying process.

All cores were further cut perpendicular to their axis in order to achieve specimens with height-to-diameter ratio of 1 . As shown in Fig. 1c, two specimens were obtained per core, with the remaining part of the core being discarded to mitigate the influence of the final stage of the spraying process. A letter was added to the label of each of the specimens obtained: "a" for the one closer to the bottom or lateral surface (Exterior) of the mould and "b" for the remaining part (Top and Interior). Finally, randomly oriented local axes were marked, indicating two orthogonal directions ( $i$ and $j$ ) and the bisector of them (ij). For convention 
purposes, the local axis parallel to the centreline of the cylindrical specimen is indicated by the letter $k$.
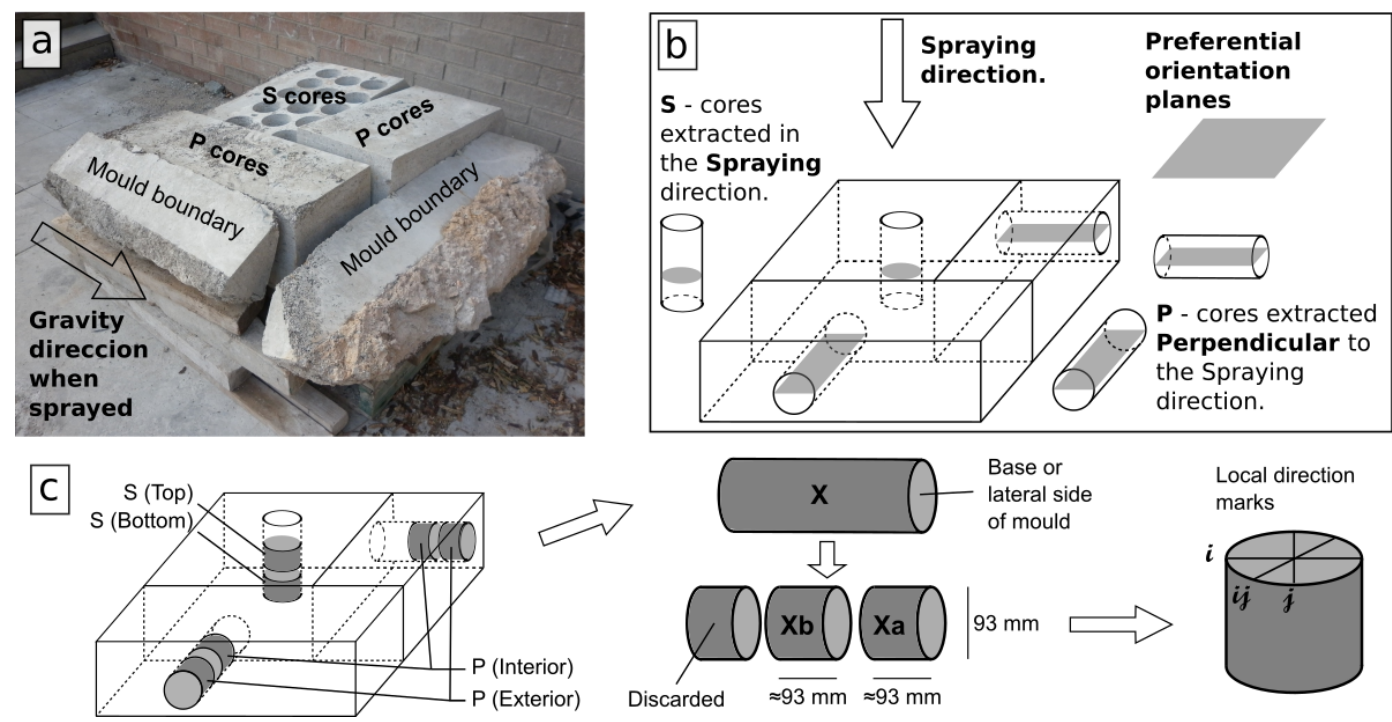

Fig. 1 a) General view of panel after cutting; b) Schematic of the core extraction directions; c) Schematic of Core preparation.

Some of the specimens were used for test trials or had to be discarded due to problems detected during extraction and cutting. From the specimens finally used in the experimental program, 8 were in the spraying direction (S02a, S02b, S03a, $\mathrm{S} 03 \mathrm{~b}, \mathrm{~S} 10 \mathrm{a}, \mathrm{S} 10 \mathrm{~b}, \mathrm{~S} 11 \mathrm{a}$ and S11b) and 6 were perpendicular to this direction (P04a, P04b, P06a, P06b, P07a and P07b).

\subsection{Fibre content and orientation evaluation}

Some studies [13], [18], [19] consider the fibre orientation in FRC through the parameter $N_{A}$, which represents the number of fibres per unit of area crossing a given plane. As shown in Eq. 1, $N_{A}$ depends on the volume of fibres in the concrete mix $\left(V_{f}\right)$, the cross-sectional area of a single fibre $\left(A_{f}\right)$ and a coefficient $(\beta)$ related with the fibre orientation, also known as "fibre efficiency factor". The coefficient $\beta$ ranges from 0 , when all fibres are perpendicular to the assessed direction, to 1 , when all the fibres are aligned with the assessed direction. A random 3D distribution of fibres was reported to have $\beta$ going from 0.2 to 0.4 .

$$
N_{A}=\beta \frac{V_{f}}{A_{f}}
$$

Other researchers [5], [6] define the parameter $\omega$ to account for the degree of anisotropy of fibre distribution. $\omega$ is 0 in case of perfect isotropy and equal to 1 if all fibres are perpendicular to the plane under evaluation. In more recent studies [20]-[22], the fibre distribution was assessed through the orientation number $\left(\eta_{n}\right)$. $\eta_{n}$ is calculated as the average of the cosine of the angle formed between each fibre from the sample and a line parallel to the direction $n$. Strong evidence suggests a proportionality between $\eta_{n}$ and the post-cracking strength of the FRC for the same fibre content [20]-[22].

The experimental assessment of fibre orientation and content was traditionally conducted either by counting of fibres at cut cross-sections or by the analysis of X-ray images of the specimens [13]. Nowadays, simpler and cheaper alternative methods are available for the same purpose [23]. The Inductive Method 
developed by Torrents et al. [24] and improved by Cavalaro et al. [25], [26] was selected in the present study. This non-destructive method has been successfully applied to assess fibre orientation and fibre content of cores extracted from realscale structures [3], [27].

The setup for the test followed the description in [25]. It consisted of a cylindrical coil made with copper cable that was connected to an inductance meter. A constant electric current was applied to the cooper cable, thus generating a magnetic field inside the coil. When steel fibres are placed inside the coil, changes are observed in the magnetic field and the inductance measured. Such changes were evaluated in four directions: one parallel (local $k$-axis) and three orthogonal ( $i$-axis, $j$-axis and $i j$-axis) to the centreline of the specimen.

These measurements were used in the equations deducted by Cavalaro et al. [26] to estimate the fibre content and the orientation number at the $k$-axis and at any direction contained in the ij plane. Equations proposed in [26] were also used to estimate the maximum and the minimum orientation numbers $\left(\eta_{\min }\right.$ and $\eta_{\max }$, respectively) in the local ij plane, as well as their position.

Furthermore, Cavalaro et al. [26] defines a parameter to evaluate the level of anisotropy $\left(\Omega_{L}\right)$ in the ij plane, which is calculated according with Eq. 2 . A $\Omega_{L}$ of 1 indicates a perfectly isotropic fibre distribution, whereas a $\Omega_{L}$ of 0 indicates a perfectly anisotropic fibre distribution. By generalizing this concept, the global isotropy factor $\left(\Omega_{G}\right)$ may be obtained as the ratio between the minimum $\eta_{\min }$ and the maximum $\eta_{\max }$ from all possible planes crossing the sample. Since only the orientation along the $k$-axis and in the ij plane are measured in the cylindrical specimens, the simplified assessment of $\Omega_{G}$ through Eq. 3 is adopted in the present study.

$$
\begin{gathered}
\Omega_{L}=\frac{\eta_{\min }}{\eta_{\max }} \\
\Omega_{G}=\frac{\min \left(\eta_{\min }, \eta_{k}\right)}{\max \left(\eta_{\max }, \eta_{k}\right)}
\end{gathered}
$$

\subsection{Residual tensile strength evaluation}

The bending tests of prismatic beam under a 3-point [28] or 4-point [29] loading configuration is the most widespread procedure used to assess the residual (post-cracking) tensile behaviour of FRC. The test of centrally loaded square [30] or rounded [31] panels is also used, especially for the characterization of sprayed FRC layers [32]. Due to the size of the specimens used in those tests, between $30 \mathrm{~kg}$ and $80 \mathrm{~kg}$ of concrete are required for each determination. Therefore, in case either of these tests was selected to assess the anisotropy, a bigger amount of material would have to be produced in order to extract elements with the required size from different directions. Besides, the shape of the specimens would significantly complicate the extraction process.

Recently, two more compact methods have been proposed to evaluate the residual tensile behaviour of FRC: the Barcelona test $(\mathrm{BCN})$ [33] and the Double Edge Wedge test (DEWS) [34]. The former is a double punch test standardized by UNE 83515:2010 [35]. A cylindrical specimen with a height-to-diameter ratio of 
1 is concentrically placed between two cylindrical steel punches with a diameter equal to a quarter of that of the specimen.

A constant relative displacement rate of $0.5 \mathrm{~mm} / \mathrm{min}$ is applied to the punches. This produces a localized compression at the top and bottom faces, causing tensile stresses inside the specimen. When the tensile stresses reach the tensile strength of the cementitious matrix, radial cracks appear. An increment of the crack opening occurs as the test continues under the same displacement rate. A circumferential extensometer placed around the specimen at its mid-height measure the total circumferential opening displacement (TCOD) produced by the cracks during the test [36].

The DEWS test is conducted with a prismatic specimen. First, triangle shaped grooves are executed at the top and bottom faces of the specimen and brass plates are glued to the surfaces of the groove. The compression is introduced by steel rollers placed in each groove that receive a constant relative displacement. This induces internal tensile stresses that produce radial cracking approximately parallel to the loading direction. LVDT installed at both sides of the specimen measure the crack opening displacement (COD). Although the DEWS generates a more determinate internal stress distribution than in the $\mathrm{BCN}$ test, it requires additional preparation and would complicate the procedure of extraction of the specimen in this experimental program. Therefore, the BCN test was chosen due to its simplicity and because of the vast experience already reported in the characterization of extracted cores.

Modifications were introduced regarding the dimension of the specimen and the assessment of the TCOD specified in the UNE 83515:2010 [35] due to the particular characteristics of the specimens used here. The original specimen diameter of $150 \mathrm{~mm}$ was reduced to $93 \mathrm{~mm}$. Consequently, the diameter of the steel punches was reduced from $37.5 \mathrm{~mm}$ to $25.0 \mathrm{~mm}$ in order to maintain approximately the proportion specified (1:4). Moreover, the circumferential extensometer was omitted and only the axial displacement between the plates of the press was assessed. Pujadas et al. [37] demonstrated that the TCOD may be estimated by the axial displacement between the plates of the press. Therefore, the test may be performed without the circumferential extensometer. The curve relating the load applied and the axial displacement between the plates of the press was obtained for each test. All modifications were previously validated in [36]-[38].

Two to four cracks usually appear during the $\mathrm{BCN}$ test [39], although one displays bigger opening than the others. The angle $\theta_{R}$ between the direction of the wider crack and the $i$-axis of the local coordinated system was also measured (See Fig. 2a). When the crack developed at just one end of the specimen (either the top or the bottom), a single angle was recorded. When the crack opened at the two ends, the average of the top and the bottom angles was calculated.

As an example, the top view and the lateral view of two cores after the BCN test are shown in Fig. $2 \mathrm{~b}$. Notice that 4 radial cracks were formed at the top of specimen S10a parallel to the loading direction. Of those, two are aligned and presented the biggest opening. Although the same number of cracks appear in specimen S11b, only one presents the biggest opening. A difference is also observed regarding the crack opening at both ends of the specimen. In the case of specimen S10a, the main crack opens preferentially at the top end, reducing significantly at the bottom end. Conversely, crack opening at the top and at the bottom ends of sample S11b are similar and a slight displacement in the crack position is observed. 

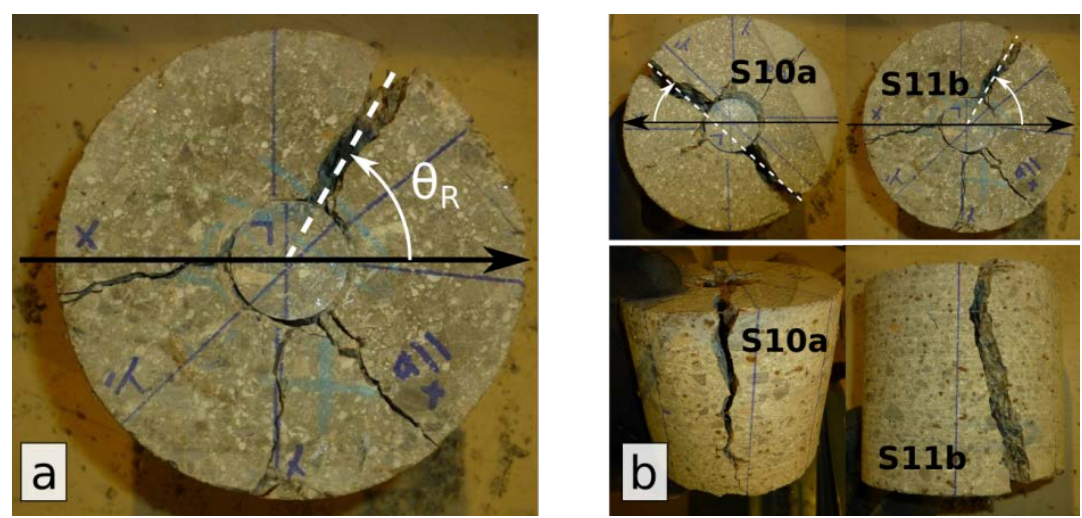

Fig. 2 a) Main crack angle $\left(\theta_{R}\right)$ measure; b) Typical cracking patterns in the $B C N$ test.

\section{FIBRE CONTENT, DISTRIBUTION AND ORIENTATION}

General results for the inductive method are summarized in Table 1, including the average fibre content, the orientation numbers and the average global isotropy factor $\left(\Omega_{G}\right)$. To simplify the interpretation of the results, the orientation numbers measured in the local axes of the specimen $\left(\eta_{i}, \eta_{j}\right.$ and $\left.\eta_{k}\right)$ were converted into the orientation numbers parallel $\left(\eta_{\|}\right)$and perpendicular $\left(\eta_{\perp, 1}\right.$ and $\left.\eta_{\perp, 2}\right)$ to the spraying direction.

The first line of the table indicates the average of all samples, whereas, in the following lines, results are grouped according with the direction or the position within the panel. The standard deviation (s.d.) and the number of specimens (n.s.) for each group are also indicated. An ANOVA analysis was performed with the results to identify if the differences observed were statistically significant. A reference significance level of 0.05 was defined for this analysis. Therefore, differences are considered statistically significant only if $p$-values smaller than 0.05 are estimated in the ANOVA analysis.

Table 1 Fibre content and orientation results

\begin{tabular}{|c|c|c|c|c|c|c|c|c|c|c|c|}
\hline & \multirow[t]{2}{*}{ n.s. } & \multicolumn{2}{|c|}{$\begin{array}{l}\text { Fibre content } \\
{[\mathrm{kg} / \mathrm{m} 3]}\end{array}$} & \multicolumn{6}{|c|}{$\begin{array}{l}\text { Orientation } \\
\text { numbers }\end{array}$} & \multicolumn{2}{|c|}{$\begin{array}{l}\text { Isotropy } \\
\text { factor }\end{array}$} \\
\hline & & Average & s.d. & $\eta_{\|}$ & s.d. & $\eta_{\perp, 1}$ & s.d. & $\eta_{\perp, 2}$ & s.d. & $\Omega_{\mathrm{G}}$ & s.d. \\
\hline Total & 14 & 26.4 & 4.5 & - & - & - & - & - & - & - & - \\
\hline$P$ cores & 6 & 24.4 & 4.1 & 0.15 & 0.09 & 0.60 & 0.03 & 0.65 & 0.03 & 0.23 & 0.14 \\
\hline S cores & 8 & 27.8 & 4.5 & 0.21 & 0.08 & 0.65 & 0.02 & 0.57 & 0.03 & 0.33 & 0.13 \\
\hline S Bottom & 4 & 30.9 & 3.8 & 0.20 & 0.07 & 0.65 & 0.01 & 0.57 & 0.04 & 0.31 & 0.11 \\
\hline S Top & 4 & 24.8 & 2.7 & 0.22 & 0.10 & 0.64 & 0.03 & 0.57 & 0.03 & 0.35 & 0.17 \\
\hline P Exterior & 3 & 23.4 & 3.3 & 0.09 & 0.09 & 0.61 & 0.03 & 0.65 & 0.04 & 0.14 & 0.14 \\
\hline $\mathrm{P}$ Interior & 3 & 25.5 & 5.4 & 0.21 & 0.06 & 0.58 & 0.03 & 0.65 & 0.00 & 0.32 & 0.09 \\
\hline
\end{tabular}

\subsection{Fibre content}

The average fibre content for all samples tested was $26.4 \mathrm{~kg} / \mathrm{m}^{3}$. This indicates a reduction of $3.6 \mathrm{~kg} / \mathrm{m}^{3}(12 \%)$ regarding the nominal fibre content added to concrete prior to spraying. Such variation could be attributed to the influence of 
the rebound and to local variation of the fibre content in the concrete mass. The only work found in the literature about the fibre content and distribution in sprayed concrete was conducted by Robins et al. [13] who used x-ray images of extracted specimens. The authors observed a reduction in the fibre content below the original nominal value of concrete, which is consistent with the findings from the present study.

Although the average fibre content in cores aligned with the spraying direction ( $S$ cores) is $13.9 \%$ bigger than that of cores perpendicular to spraying direction ( $P$ cores), a p-value of 0.172 is obtained, showing that differences are not statistically significant. Since the material is approximately in the same region of the panel regardless of the direction of extraction, no clear difference is observed. An analogous conclusion comes from the comparison of the fibre content of $P$ specimens depending on their position. Negligible difference exists between those located closer to the exterior of the panel ( $P$ Exterior) and those located closer to the interior of the panel (P Interior), as p-values of 0.596 are obtained. Conversely, a significant difference in the fibre content is found depending on the position of specimens along the thickness. Those located closer to the mould surface (S Bottom) have an average fibre content $24.6 \%$ higher than the obtained for those farther from the mould surface (S Top), with a p-value of 0.040. In other words, more fibres are expected close to the substrate.

An in depth analysis of the results by Robins et al. [13] suggest a nearly uniform fibre distribution along the thickness and in the plane perpendicular to it. Although this is consistent with the findings presented here about the influence of the inplane position, it does not agree with the observed along the thickness. Notice that Robins et al. [13] characterized $7.5 \mathrm{~cm}$ thick layers, in contrast with the approximately $18.6 \mathrm{~cm}$ layers used here. The variation in the geometry of the sample and in the technique used to quantify the fibre content could justify the differences observed between both studies in this matter.

To understand why the influence of the position appears along the thickness but not along the perpendicular plane, the distance regarding the surface of the mould should be considered. S specimens were extracted as close as possible to the mould, while $P$ specimens were at least at least $20 \mathrm{~cm}$ apart from the lateral side of the mould since the edges of the panel had to be removed (see section 2.1). Therefore, the influence of the moulds in terms of the rebound should be more noticeable along the thickness due to the proximity.

The bigger fibre content found close to the surface could suggest an increase of the fibre rebound as the spraying gets farther from the surface of the mould. Nevertheless, this reasoning contradicts common knowledge about the spraying process. In fact, the placement of the first layers close to the surface of the metallic mould should be subjected to a bigger rebound due to the impact of particles directly at a solid surface. Once the first layers of sprayed concrete are placed, they should act as a softer bedding that favours the retention of incoming sprayed material. Consequently, the rebound should be smaller in the following layers if the execution procedure is maintained.

In this context, the finding described here cannot be justified solely by a variation of the fibre rebound with the thickness. Instead, it could be a consequence of a differential rebound of the components of the concrete mix. As mentioned previously, the rebound occurs mainly in coarser fraction of the aggregates and the fibres as a result of their size and shape. However, the intensity of the phenomenon in each material could differ along the thickness. Due their bigger weight and more rounded shape, aggregate particles would be more likely to 
rebound in the initial stages of the spraying process when they impact at the solid metallic mould. On the contrary, the low mass and the stretched shape of the fibres would make it more likely to be retained by the incoming sprayed material in this stage. If this happened, a bigger proportion of coarse aggregate would rebound so that, proportionally, the content of fibre in the layer could increase.

Once the first sprayed layers are formed over the surface, the rebound of the coarse aggregate would reduce as the kinetic energy of the particles would be converted into a plastic deformation of the existing layer instead of kinetic energy moving particles backwards. This reduction in rebound would be less evident in the case of the fibres. Therefore, after the first layers are placed, the rebound of the aggregates should reduce more than that of the fibres. Since coarser aggregate would occupy a bigger volume of the new layers of concrete, proportionally less fibre would be present. Further experimental work is required to evaluate this hypothesis.

\subsection{Fibre orientation}

Table 1 presents the orientation numbers calculated in different directions. Similar average values are obtained for the two directions perpendicular to the spraying $\left(\eta_{\perp, 1}\right.$ and $\left.\eta_{\perp, 2}\right)$, both being close to 0.60 . This indicates the absence of preferential orientations among the axes perpendicular to the spraying direction. On the contrary, the orientation number parallel to the spraying direction $\left(\eta_{\|}\right)$is close to 0.2 , i.e. nearly 3 times smaller than the found perpendicular to the spraying direction.

This indicates a strong preferential orientation of the fibres, which tend to assume a position perpendicular to the spraying direction and parallel to the wall of the moulds. When one of the ends of the fibres impact against the substrate, the remaining quantity of movement favours a spin of the other end towards an arrangement parallel to the sprayed layer. This movement is also favoured by the impact of incoming material from the following layers.

The difference between $\eta_{/ /}$and $\eta_{\perp}$ is maintained in specimens extracted near the mould ( $S$ bottom) and farther from it ( $S$ top), revealing that the preferential orientation appears regardless of the position along the thickness. The global isotropy factor $\left(\Omega_{G}\right)$ assessed with Eq. 3 confirms that a strong fibre preferential orientation exists in all specimens characterized. Average values below 0.35 were obtained. Consequently, the specimens are closer to perfect anisotropy $\left(\Omega_{G}=0\right)$ than to perfect isotropy $\left(\Omega_{G}=1\right)$.

Fig. 3a shows the curves of the orientation profile measured in planes parallel and perpendicular to the spraying direction, which were obtained for the local ij planes of specimens $P$ and $S$, respectively. To facilitate the comparison, the curves were shifted to make the maximum orientation number coincide with the angle $\theta$ equal to $0^{\circ}$. Grey areas indicate the range of curves for each plane.

Results confirm that the orientation number is nearly uniform in all axes perpendicular to the spraying direction, showing similar values of $\eta_{\min }$ and $\eta_{\max }$. The opposite occurs in the plane parallel to the spraying direction. The curves reveal a small proportion of fibres aligned with the $90^{\circ}$ angle (parallel to the spraying direction) and a significant amount of fibres aligned with the $0^{\circ}$ angle (perpendicular to the spraying direction). In this last case, $\eta_{\max }$ is several times bigger than $\eta_{\min }$. Such outcome corroborates the previous observations. 

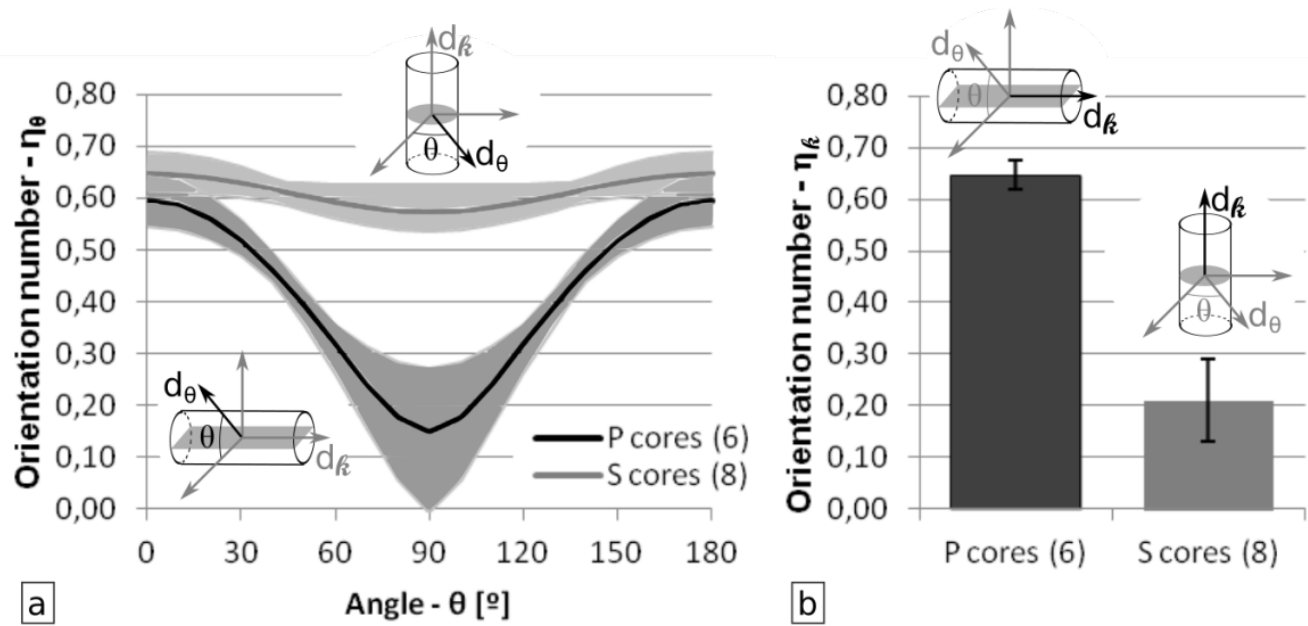

Fig. 3 Fibre orientation profile.

\section{RESIDUAL TENSILE BEHAVIOUR}

\subsection{General mechanical results}

Three main phases can be distinguished in terms of the behaviour of the specimen during the BCN test. In phase 1, the load applied is transmitted through the matrix without the formation of cracks. Phase 2 initiates once the tensile strength of the matrix is reached and cracks are formed. In Phase 3 all cracks are formed and the different parts of the sample are pushed apart. A detailed description of the fracture mechanics of the BCN test is presented in [37].

Table 2 shows the maximum load $\left(F_{\max }\right)$, the load at $0.02 \mathrm{~mm}$ of axial displacement of the piston of the press $\left(F_{0,02}\right)$ and the load at $2.66 \mathrm{~mm}$ of axial displacement of the piston of the press $\left(F_{2,66}\right)$. Notice that $F_{0,02}$ and $F_{2,66}$ are related with the stress level in Phase 3 of the BCN test.

No significant difference is found in the comparison of $F_{\max }$ depending on the direction of the specimen ( $P$ and $S$ ), the position along the thickness ( $S$ Bottom and $S$ Top) and the position in the plane perpendicular to the spraying direction ( $P$ Exterior and $P$ interior). In all cases, $p$-values are above 0.05. According with [40], $F_{\max }$ is mainly related with the mechanical characteristics of the cementitious matrix for fibre contents below $1 \%$ by volume. Since the matrix is nearly the same in all specimens, similar results are obtained, regardless of the changes in fibre orientation.

The potential influence of the fibre orientation is observed in the post-cracking stage, when they are responsible for bridging the cracks and providing residual bearing capacity. In line with that, the average $F_{0,02}$ in $S$ specimens is 3.2 times bigger than that of $P$ specimens, with a $p$-value of 0.00 . These specimens are loaded and present radial cracks parallel to the spraying direction. As described in the previous section, fibres tend to align perpendicular to the spraying direction, hence bridging the radial cracks in the S specimen. Conversely, at least one of the crack surfaces observed during the BCN test of $P$ specimens could form high angles (close to $90^{\circ}$ ) with the spraying direction. Such surface would approximate the plane of preferential fibre orientation, which implies a significant reduction of the number and the efficiency of the fibres bridging the cracks in the case of $P$ specimens. 
Table 2 Representative load results for the mechanical tests.

\begin{tabular}{|c|c|c|c|c|c|c|c|c|c|c|}
\hline & \multirow[t]{2}{*}{ n.s. } & \multicolumn{3}{|l|}{$F_{\max }$} & \multicolumn{3}{|l|}{$\mathrm{F}_{0,02}$} & \multicolumn{3}{|l|}{$F_{2,66}$} \\
\hline & & $\begin{array}{l}\text { Av. } \\
{[\mathrm{kN}]}\end{array}$ & $\begin{array}{l}\text { s.d. } \\
\text { [kN] }\end{array}$ & $\begin{array}{l}\text { C.V. } \\
{[\%]}\end{array}$ & $\begin{array}{l}\text { Av. } \\
{[\mathrm{kN}]}\end{array}$ & $\begin{array}{l}\text { s.d. } \\
{[\mathrm{kN}]}\end{array}$ & $\begin{array}{l}\text { C.V. } \\
{[\%]}\end{array}$ & $\begin{array}{l}\text { Av. } \\
{[\mathrm{kN}]}\end{array}$ & $\begin{array}{l}\text { s.d. } \\
{[k N]}\end{array}$ & $\begin{array}{l}\text { C.V. } \\
{[\%]}\end{array}$ \\
\hline P cores & 6 & 57.3 & 20.7 & 36.1 & 14.7 & 6.6 & 45.1 & 1.5 & 1.0 & 69.3 \\
\hline S cores & 8 & 68.1 & 5.6 & 8.2 & 47.1 & 5.8 & 12.4 & 5.5 & 2.6 & 47.8 \\
\hline S-Bottom & 4 & 68.1 & 5.6 & 8.3 & 47.8 & 3.0 & 6.3 & 6.6 & 3.3 & 49.8 \\
\hline S-Top & 4 & 68.0 & 6.3 & 9.3 & 46.5 & 8.3 & 17.9 & 4.5 & 1.6 & 36.6 \\
\hline P-Exterior & 3 & 46.6 & 25.9 & 55.5 & 19.5 & 2.2 & 11.3 & 1.5 & 0.7 & 46.4 \\
\hline P-Interior & 3 & 68.0 & 7.4 & 10.8 & 9.9 & 6.0 & 60.3 & 1.5 & 1.5 & 101.3 \\
\hline
\end{tabular}

The difference in the residual tensile behaviour should increase as the crack opening grows and the fibres are activated. For instance, $F_{2,66}$ in $\mathrm{S}$ specimens is 3.7 times bigger than that of $P$ specimens, with a $p$-value of 0.00 . These results confirm that the strong anisotropy in the fibre distributions produces an equally strong anisotropy in the mechanical post-cracking response of SSFRC depending on the direction of characterization.

The assessment of the influence of the position along the thickness (S Bottom and $S$ Top) and the position in the plane perpendicular to the spraying direction ( $P$ Exterior and $P$ interior) yield $p$-values above 0.05 . In other words, no statistically significant difference was observed in any of the residual tensile forces analysed. This is in line with the findings of fibre orientation described in section 3.2 that indicate negligible variation in the fibre orientation depending on the position inside the panel.

Fig. 4 shows the load-axial displacement curves for the BCN test for $\mathrm{S}$ specimens and $\mathrm{P}$ specimens. Only the post-cracking stage (Phase 3 ) is represented in order to simplify the assessment of the mechanical anisotropy. The displacement values were offset to start at $0.0 \mathrm{~mm}$ after the first crack. Shaded areas indicate the range of individual values, with the average for each specimen in continuous line.

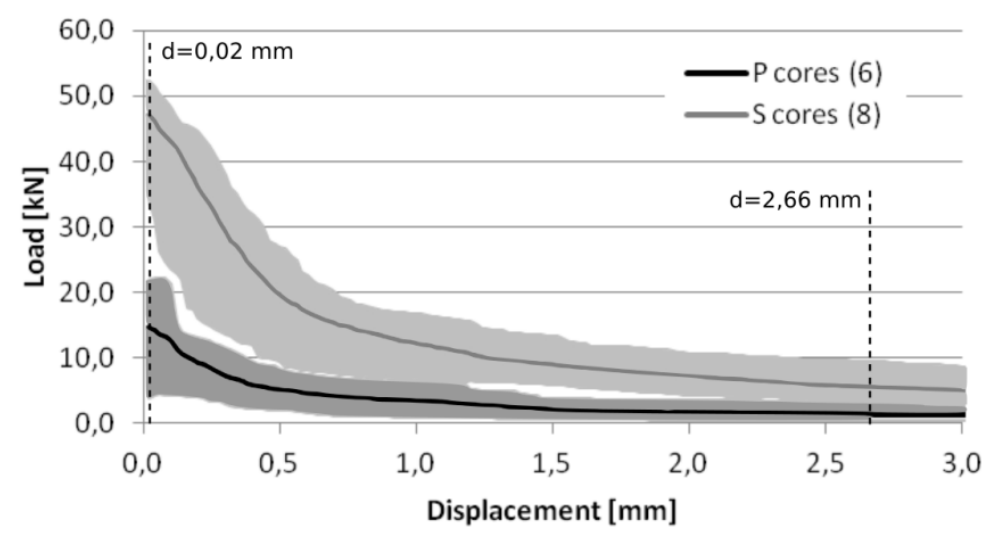

Fig. 4 Load-axial displacement.

The difference in behaviour depending on the direction of characterization appears along the whole extent of axial displacement measured, confirming the anisotropy in the mechanical response. The better performance in terms of load resisted and energy absorbed when the cracks appear parallel the spraying direction ( $S$ specimens) is favourable in the majority of sprayed concrete structures. In fact, these structures are normally loaded perpendicular to their 
surface, i.e. nearly parallel to the spraying direction. This produces a cracking patter similar to the observed in S specimens, which maximizes the contribution of the fibres to the residual tensile response.

\section{CORRELATION BETWEEN FIBRE ORIENTATION AND MECHANICAL RESULTS}

In this section, the mode of failure for the specimens is further analysed, illustrating how the fibre anisotropy affects the cracking pattern in the BCN test. First, the angle of the main crack is related with the fibre orientation. Then, the strength is correlated with the orientation number in the plane of cracking.

\subsection{Influence of fibre orientation on main crack direction}

Fig. 5 shows for each specimen tested the relation between the angle difference $(\Delta \theta)$ and the local isotropy factor $\left(\Omega_{L}\right)$ in the ij-plane, which is perpendicular to the cracks in the BCN test. The $\Delta \theta$ is defined as the absolute difference between the angle of the main crack $\left(\theta_{R}\right)$ in the $\mathrm{BCN}$ test and the angle for the maximum fibre orientation $\left(\theta_{\max }\right)$ in the inductive method, as represented by Eq. 4 and illustrated by Fig. 8. Notice that the same local coordinate system is used to assess all angles in order to avoid inconsistencies.

$$
\Delta \theta=\left|\theta_{R}-\theta_{\max }\right|
$$

Eq. 4

Specimens with high local anisotropy in plane perpendicular to the cracks ( $P$, which showed $\Omega_{L}<0.6$ ) have $\Delta \theta$ ranging from 0 to $20^{\circ}$. On the contrary, specimens with low local anisotropy (S, which showed $\left.\Omega_{L}>0.6\right)$ have $\Delta \theta$ ranging from 0 and $55^{\circ}$. This means that the relation between the direction of cracking and the direction with the highest orientation number is more evident in specimens with high anisotropy, extracted perpendicular to the spraying direction.

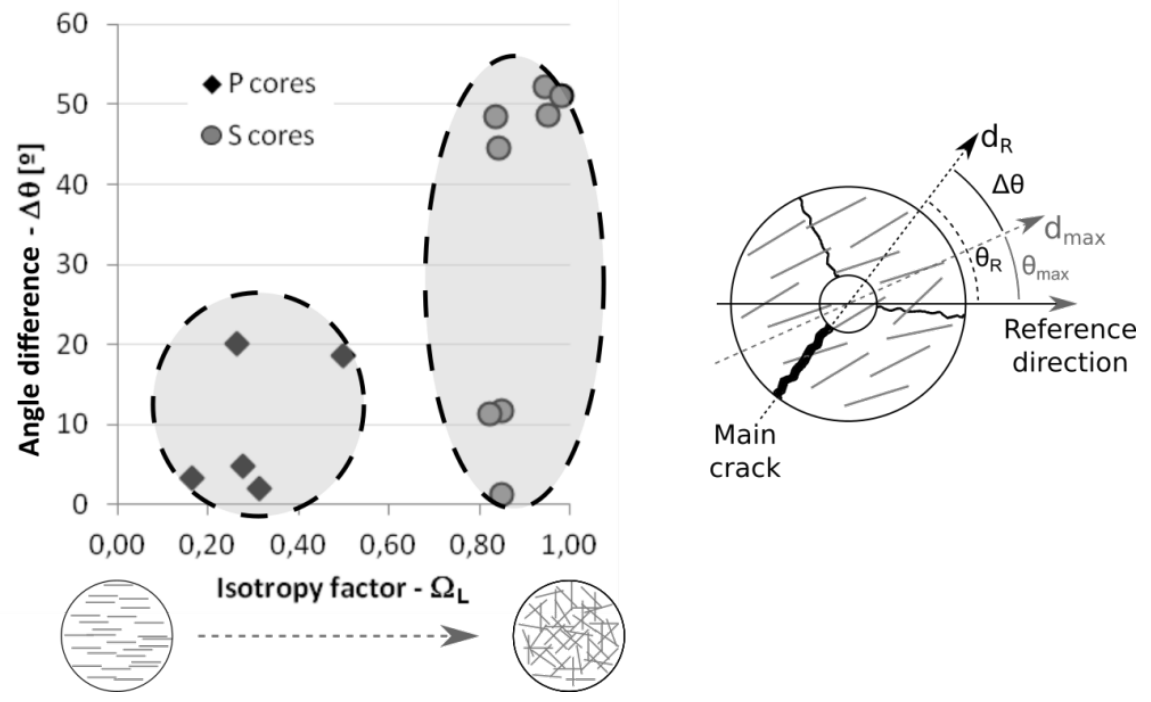

Fig. 5 Relation between angle difference and isotropy factor in the ij-plane (plane perpendicular to the cracks) of each core.

This behaviour could be attributed to two factors. On the one hand, as the sprayed concrete is built up in successive accumulative layers, the contact between layers may present a slightly weaker plane, where the crack is more 
likely to initiate and propagate. On the other hand, the preferential fibre orientation perpendicular to spraying direction lead to planes with less capacity to control micro-crack propagation. Once the cracks are formed, the presence of a smaller number and less efficiently oriented fibres favours the opening through these planes perpendicular to the spraying direction.

This suggests that the result from the BCN test takes into account the anisotropy of the fibre distribution. Unlike other procedures, the crack formation is not localized in a specific position of the specimen so that cracks may form and open at the weakest sections.

\subsection{Load vs orientation number}

Fig. 6a shows the relation between the residual load measured with the $\mathrm{BCN}$ test and the orientation number in the radial direction orthogonal to the main crack $\left(\eta_{E}\right)$ for the same specimen. An $\mathrm{R}^{2}$ of 0.89 is observed in the linear regression with the results of $F_{0,02}$. The residual tensile strength is influenced by the orientation of fibres crossing the crack, which is directly correlated with the orientation number [20]-[22]. For larger displacements $\left(F_{2,66}\right)$, although the tendency remains, the correlation is less clear $\left(R^{2}=0,47\right)$, partially because the absolute values of residual strengths are much smaller. Fig. $6 \mathrm{~b}$ shows the relation between residual loads and the orientation number in the direction of minimum fibre contribution $\left(\eta_{\min }\right)$. The correlation and the observation are analogous to the ones described for $\eta_{E}$.
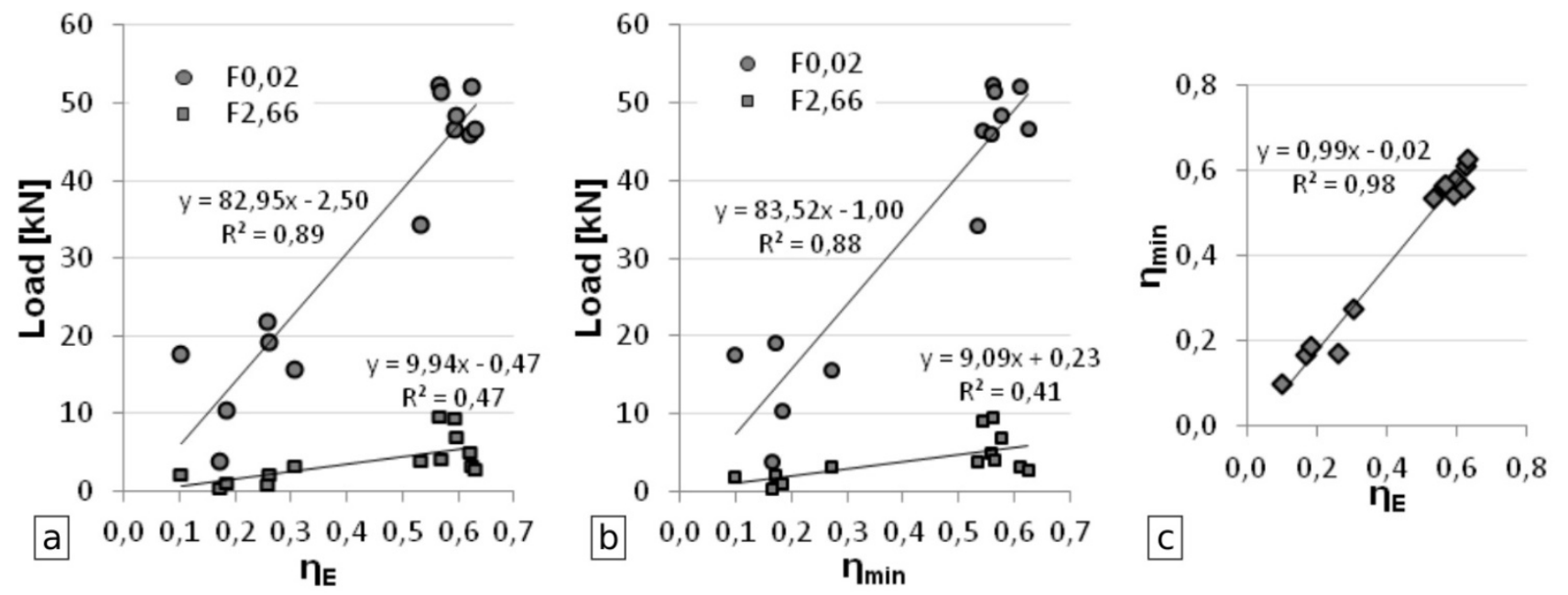

Fig. 6 Relations between residual load, orientation number perpendicular to the main crack and the minimum orientation number.

Fig. $6 \mathrm{c}$ presents the relation between $\eta_{E}$ and $\eta_{\min }$. Since the main crack in the $\mathrm{BCN}$ test tends to open perpendicular to the direction with smallest fibre content, $\eta_{E}$ is well correlated with $\eta_{\min }$, showing an $\mathrm{R}^{2}$ of 0.98 and a slope that approaches the equality. This means that the $\eta_{\min }$ estimated with the inductive method may be taken as a reference for the $\eta_{E}$ perpendicular to the plane that will present the main crack in the $\mathrm{BCN}$ test. 


\section{CONCLUSIONS}

The following conclusions are derived based on the results and analysis presented in this study.

- In general, the fibre content of the sprayed panel is smaller than the nominal content placed in the concrete. This is attributed to the rebound of the fibres, which in this case was of approximately $13 \%$ by weight of the initial nominal content.

- The fibre content is not affected by the direction or the position along the plane of the sprayed layer from which specimens are extracted. On the contrary, results suggest that the position along the thickness may induce variations in the fibre content. This parameter was $24.6 \%$ bigger in specimens extracted closer to the surface of the mould in comparison to those farther from the same surface. The main cause may be related with the differential rebound of the fibres and the coarse aggregate in the first layers of concrete placed close to the mould. Additional studies are required to confirm or reject this hypothesis.

- A strong preferential orientation of the fibres occurs as a result of the shearing conditions of the spraying process. Fibres tend to spin and align perpendicularly to the spraying direction. Results indicate that the orientation number perpendicular to the spraying direction is 3 times bigger the orientation number parallel to the spraying direction. No significant influence of the position of the specimen along the thickness or in the in-plane position was found.

- A strong anisotropy in the tensile residual response is observed due to the preferential orientation of the fibre depending on the direction of the characterization. Specimens loaded parallel to the spraying direction show residual load around 3.5 bigger than those loaded perpendicular to the spraying direction. Such anisotropy should be considered in the structural design of sprayed concrete elements, especially if cracks perpendicular to the spraying direction are expected.

- The direction of the main cracks formed in the $\mathrm{BCN}$ test tends to approximate the direction with the smallest orientation number measured with the inductive method. This shows that the BCN test is sensible to the weakest cracking plane. The combination of both methods using the same specimen provides valuable information to estimate and understand the behaviour of fibre reinforced concrete, especially in case of applications through spraying.

\section{ACKNOWLEDGMENTS}

The authors would like to thank the Spanish Ministry of Science and Innovation for the economic support received through Research Project IPT F-00339 FIBHAC.

The authors declare that they have no conflict of interest. 
This is a pre-print of an article published in Materials and Structures. The final authenticated version is available online at: https://doi.org/10.1617/s11527-018$1156-5$

\section{REFERENCES}

[1] J. Edgington and D. J. Hannant, "Steel fibre reinforced concrete. The effect on fibre orientation of compaction by vibration," Matériaux Constr., vol. 5, no. 1, pp. 41-44, 1972.

[2] L. Ferrara, N. Ozyurt, and M. de Prisco, "High mechanical performance of fibre reinforced cementitious composites : the role of " casting-flow induced "' fibre orientation," Mater. Struct., vol. 44, no. 1, pp. 109-128, 2011.

[3] A. Blanco, P. Pujadas, A. de la Fuente, S. H. P. Cavalaro, and A. Aguado, "Assessment of the fibre orientation factor in SFRC slabs," Compos. Part B, vol. 68, pp. 343-354, 2015.

[4] F. Laranjeira, a. Aguado, C. Molins, S. Grünewald, J. Walraven, and S. Cavalaro, "Framework to predict the orientation of fibers in FRC: A novel philosophy," Cem. Concr. Res., vol. 42, no. 6, pp. 752-768, Jun. 2012.

[5] R. Gettu, D. R. Gardner, H. Saldívar, and B. E. Barragán, "Study of the distribution and orientation of fibers in SFRC specimens," Mater. Struct., vol. 38, no. 1, pp. 31-37, Dec. 2005.

[6] P. Stroeven, "The analysis of fibre distributions in fibre reinforced materials," $J$. Microsc., vol. 111, no. 3, pp. 283-295, 1977.

[7] P. Stähli, R. Custer, and J. G. M. van Mier, "On flow properties, fibre distribution, fibre orientation and flexural behaviour of FRC," Mater. Struct., vol. 41, no. 1, pp. 189196, Feb. 2008.

[8] S. J. Barnett, J. Lataste, T. Parry, S. G. Millard, and M. N. Soutsos, "Assessment of fibre orientation in ultra high performance fibre reinforced concrete and its effect on flexural strength," Mater. Struct., vol. 43, no. 7, pp. 1009-1023, 2010.

[9] Fédération Internationale du Béton, fib Model Code for Concrete Structures 2010. Lausanne, 2013.

[10] A. Blanco, S. Cavalaro, A. de la Fuente, S. Grünewald, C. B. M. Blom, and J. C. Walraven, "Application of FRC constitutive models to modelling of slabs," Mater. Struct., vol. 48, no. 9, pp. 2943-2959, 2015.

[11] P. Serna, S. Arango, T. Ribeiro, a. M. Núñez, and E. Garcia-Taengua, "Structural cast-in-place SFRC: technology, control criteria and recent applications in spain," Mater. Struct., vol. 42, no. 9, pp. 1233-1246, Jul. 2009.

[12] H. S. Armelin and P. Helene, "Physical and Mechanical Properties of Steel Fiber Reinforced Dry-Mix Shotcrete," ACI Mater. J., vol. 92, no. 3, pp. 258-267, 1995.

[13] P. J. Robins, S. Austin, and P. A. Jones, "Spatial distribution of steel fibres in sprayed and cast concrete," Mag. Concr. Res., vol. 55, no. 3, pp. 225-235, Jan. 2003.

[14] N. Banthia, J. Trottier, and D. Beaupré, "Steel-Fiber-Reinforced Wet-Mix Shotcrete: Comparisons with Cast Concrete," J. Mater. Civ. Eng., vol. 6, no. 3, pp. 430437, Aug. 1994.

[15] L. Segura-Castillo and A. Aguado De Cea, "Bi-layer diaphragm walls: Evolution of concrete-to-concrete bond strength at early ages," Constr. Build. Mater., vol. 31, pp. 2937, 2012.

[16] L. Segura-Castillo, "Bi-layer diaphragm walls: Experimental and numerical analysis.," Universidad Politéncia de Cataluña. Barcelona, Spain, 2013.

[17] AENOR, UNE-EN 14488-1:2006 Testing sprayed concrete - Part 1: Sampling fresh and hardened concrete. 2006.

[18] H. Krenchel, "Fibre spacing and specific fibre surface," in Proceedings of RILEM symposium on fibre reinforced cement and concrete, 1975, pp. 69-79.

[19] P. Soroushian and C.-D. Lee, "Distribution and Orientation of Fibers in Steel Fiber Reinforced Concrete," ACI Mater. J., vol. 87, no. 5, pp. 433-439, 1990.

[20] A. G. Kooiman, "Modelling Steel Fibre Reinforced Concrete for Structural Design," Delft University of Technology, 2000.

[21] B. Barragán, "Failure and toughness of steel fiber reinforced concrete under tension and shear.," Universitat Politècnica de Catalunya, 2002. 
[22] S. Grünewald, "Performance-based design of self-compacting fibre reinforced concrete.," Delft University of Technology, The Netherlands, 2004.

[23] P. Pujadas, A. Blanco, S. H. P. Cavalaro, A. de la Fuente, and A. Aguado, "Multidirectional double punch test to assess the post-cracking behaviour and fibre orientation of FRC," Constr. Build. Mater., vol. 58, pp. 214-224, May 2014.

[24] J. M. Torrents, A. Blanco, P. Pujadas, A. Aguado, P. Juan-García, and M. Á. Sánchez-Moragues, "Inductive method for assessing the amount and orientation of steel fibers in concrete," Mater. Struct., vol. 45, no. 10, pp. 1577-1592, Apr. 2012.

[25] S. H. P. Cavalaro, R. López, J. M. Torrents, and A. Aguado, "Improved assessment of fibre content and orientation with inductive method in SFRC," Mater. Struct., Mar. 2014.

[26] S. H. P. Cavalaro, R. López-Carreño, J. M. Torrents, A. Aguado, and P. JuanGarcía, "Assessment of fibre content and 3D profile in cylindrical SFRC specimens," Mater. Struct., 2015.

[27] A. Orbe, J. Cuadrado, R. Losada, and E. Rojí, "Framework for the design and analysis of steel fiber reinforced self-compacting concrete structures," Constr. Build. Mater., vol. 35, pp. 676-686, 2012.

[28] EN 14651, "Test method for metallic fibre concrete - Measuring the flexural tensile strength (limit of proportionality ( LOP ), residual )." 2005.

[29] NBN B 15-238, "Test on fibre reinforced concrete - bending test on prismatic simples. Norme Belge, Institut Belge de Normalisation, Brussels (in French)." 1992.

[30] EFNARC, European Specification for Sprayed Concrete, European Federation of Producers and Applicators of Specialist Products for Structures. 1996.

[31] ASTM C1550-10a, "Standard Test Method for Flexural Toughness of Fiber Reinforced Concrete ( Using Centrally Loaded Round Panel )," ASTM Stand., pp. 1-14, 2012.

[32] E. S. Bernard, "Correlations in the behaviour of fibre reinforced shotcrete beam and panel specimens," Mater. Struct., vol. 35, no. 3, pp. 156-164, 2002.

[33] C. Molins, A. Aguado, and S. Saludes, "Double Punch Test to control the energy dissipation in tension of FRC (Barcelona test)," Mater. Struct., vol. 42, no. 4, pp. 415-425, May 2009.

[34] M. di Prisco, L. Ferrara, and M. G. L. Lamperti, "Double edge wedge splitting (DEWS ): an indirect tension test to identify post-cracking behaviour of fibre reinforced cementitious composites," Mater. Struct., vol. 46, pp. 1893-1918, 2013.

[35] AENOR, "UNE 83515 - Fibre reinforced concrete. Determination of cracking strength, ductility and residual tensile strength. Barcelona Test." p. 10, 2010.

[36] A. Blanco, P. Pujadas, S. Cavalaro, A. De La Fuente, and A. Aguado, "Constitutive model for fibre reinforced concrete based on the Barcelona test," Cem. Concr. Compos., vol. 53, pp. 327-340, 2014.

[37] P. Pujadas, A. Blanco, S. Cavalaro, A. de la Fuente, and A. Aguado, "New Analytical Model To Generalize the Barcelona Test Using Axial Displacement," J. Civ. Eng. Manag., vol. 19, no. 2, pp. 259-271, 2013.

[38] C. Aire, C. Molins, and A. Aguado, "Ensayo de doble punzonamiento para concreto reforzado con fibra: efecto del tamaño y origen de la probeta.," Concreto y Cem. Investig. y Desarro., vol. 5, no. 1, pp. 17-31, 2013.

[39] S. Carmona Malatesta, A. Aguado de Cea, and C. Molins Borrell, "Generalization of the Barcelona test for the toughness control of FRC," Mater. Struct., vol. 45, no. 7, pp. 1053-1069, Jan. 2012.

[40] M. di Prisco, G. Plizzari, and L. Vandewalle, "Fibre reinforced concrete: new design perspectives," Mater. Struct., vol. 42, no. 9, pp. 1261-1281, Sep. 2009. 